\title{
113
}

\section{SERVO-HYDRAULIC REAL CRASH AND INVERSE CRASH SYSTEMS}

\author{
Dr. Ing. Peter WÜSTHOF \\ Mannesmann Rexroth AG \\ Rexroth Hydraulics \\ P.O.Box 340, D-97813 Lohr am Main
}

\begin{abstract}
To make stored potential energy available in milliseconds is a physical advantage of hydraulics. Acceleration of masses using high momentary power by installing small average power can only be achieved with hydraulic systems. Two newly developed practical applications will be explained.

A real crash system for automotive testing makes over $500 \mathrm{~kW}$ available with $30 \mathrm{~kW}$ installed power. Acceleration and speed is achieved by secondary controlled hydraulic rotary unit.

An inverse crash system for simulated automotive testing makes $40.000 \mathrm{~kW}$ available with an installed power of 100 $\mathrm{kW}$. The acceleration profile is achieved by a linear servo unit using a four stage servo valve.
\end{abstract}

\section{KEY WORDS}

\section{REAL AND INVERSE CRASH SYSTEMS}

1. Advantage of hydraulic energy storage Hydraulics offers the possibility of storing energy and to convert it into power within a short time. The hydraulic energy potential is dynamically available within a few milliseconds. No other type of drive can utilize this flexible energy storage technique. Electrical and mechanical types of storage in the form of batteries and flywheels may have a considerably higher energy density (factor 10 to 100), however, the energy cannot be converted in a comparable way into peak power for spontaneous utilization.

The basic elements of hydraulic energy storage are hydropneumatic bladder-type and piston-type accumulators. Under the assumption of isentropic changes of state, the energy content of these accumulators can be calculated as follows: 
$\left.W_{12}=\frac{p_{1} V_{1}}{k-1} \mid\left(\frac{p_{1}}{p_{2}}\right)^{\frac{1-k}{k}}-1\right]$

As the lowest operating pressure $p_{1}$ used is determined by the charging pressure on the gas side, the maximum energy capacity with regard to nitrogen as energy carrier is as follows:

$$
\mathrm{W}_{12}=0.308 \cdot \mathrm{V}_{1} \mathrm{p}_{2}
$$

According to this, at best $30 \%$ of the enclosed accumulator chamber $\mathrm{V}_{1}$ can be utilized for converting energy. This value can be improved by employing additional nitrogen capacities. Especially in connection with piston-type accumulators it is common practice to connect nitrogen bottles downstream in order to increase the actual energy content of the piston-type accumulator.

As a result of the use of hydropneumatic accumulators, hydraulic systems can be operated using a lower installed primary or pump power. Expensive electrical peak power from the mains is, therefore, not required.
Many industrial sectors benefit from this solution. The heavy machinery sector, the plastics processing machinery industry, stage technology and testing engineering are only a few examples. The low installed power for high peak power requirements is also the reason for utilizing hydraulics for driving servohydraulic real crash and inverse crash systems.

\section{Real crash system}

The ever increasing safety demands made on vehicles led to the necessity of using crash systems which allow the precise and repeatable setting of testing parameters. This helps to gain useful knowledge with regard to safe and at the same time ergonomic vehicle designs. With the real crash system presented here, the vehicle is drawn by a winch against a crash obstacle using an endless rope with clamping device (Fig. 1). The vehicle is released shortly before the crash. Special cameras and sensors document the visual and measurable parameters of dummies and vehicles in the order of milliseconds.

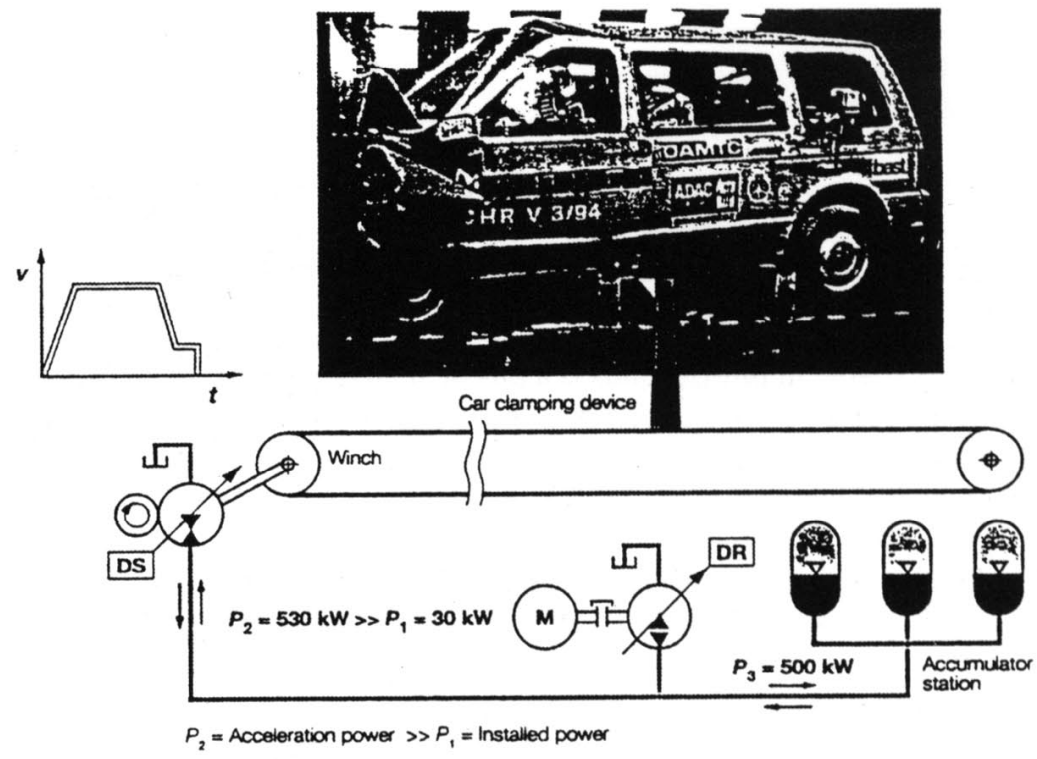

Fig. 1 Hydraulic drive principle of a real crash system

\subsection{The hydraulic drive}

The power stored for acceleration is $500 \mathrm{~kW}$. Compared with that, the installed electric-hydraulic power is only $30 \mathrm{~kW}$. After a crash test has been carried out with full power, the accumulator station, which consists of a piston-type accumulator and downstream nitrogen bottles, will be recharged within only a few minutes. For this purpose, a pressure- compensated axial piston pump (A4VSO40DR) is provided. The drive is able to accelerate a car having a mass of $3.5 \mathrm{t}$ to $80 \mathrm{~km} / \mathrm{h}$, or a truck having a mass of $9 \mathrm{t}$ to $50 \mathrm{~km} / \mathrm{h}$ within a distance of $55 \mathrm{~m}$. The accuracy of the vehicle speed is $0.3 \mathrm{~km} / \mathrm{h}$ under any operating condition.

The rope winch is driven by two axial piston units (type A4VSO500DS), which are mounted onto a splitter gearbox. They operate as speed-controlled units 
according to the principle of secondary control (Fig. 2). During the acceleration phase, the axial piston units operate as hydraulic motors and can exactly follow the given speed profile. This is essential with regard to the process, as even small speed overshoots have a negative effect on the vehicle velocity due to the elasticity of the almost $200 \mathrm{~m}$ long rope.
The maximum power that can be output by secondary units during the acceleration phase or recovered during the braking phase in the pump mode is $530 \mathrm{~kW}$. The secondary controlled drive has no throttling points in the high-pressure line and thus ensures highest efficiency while offering good controllability. The system, therefore, does not require any oil cooling.

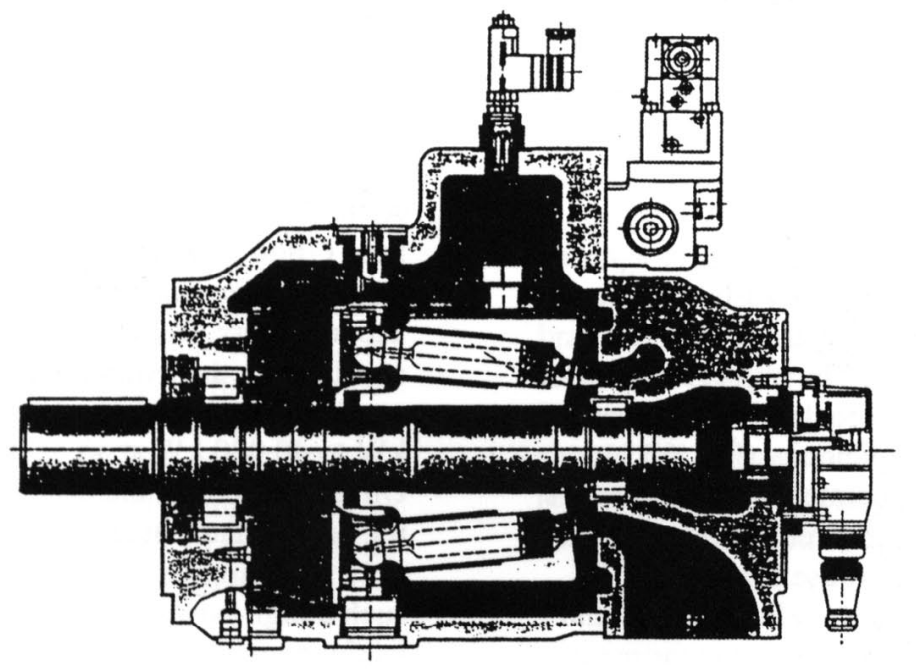

Fig. 2 Axial piston unit with control of secondary unit

\subsection{Control principle}

The closed-loop control of the secondary controlled drive allows the selection of any velocity profile. The deviations of actual values from command values are very small (Fig. 3). The controller hardware used is a digital electronic assembly (type DRB2).

The real crash system is controlled from a PC which forms the interface with the operator. Windows operator interfaces allow fast and easy access to parameterize the system. The PC that is located in the control room can, via a network, access the electronic switch cabinet of the system, where real-time tasks such as command value preselection and measured data acquisition are performed by a real-time computer (Fig. 4). A PLC is used for automation purposes. Thus, a modern, decentralized control concept with familiar operator guidance is available for handling the system.

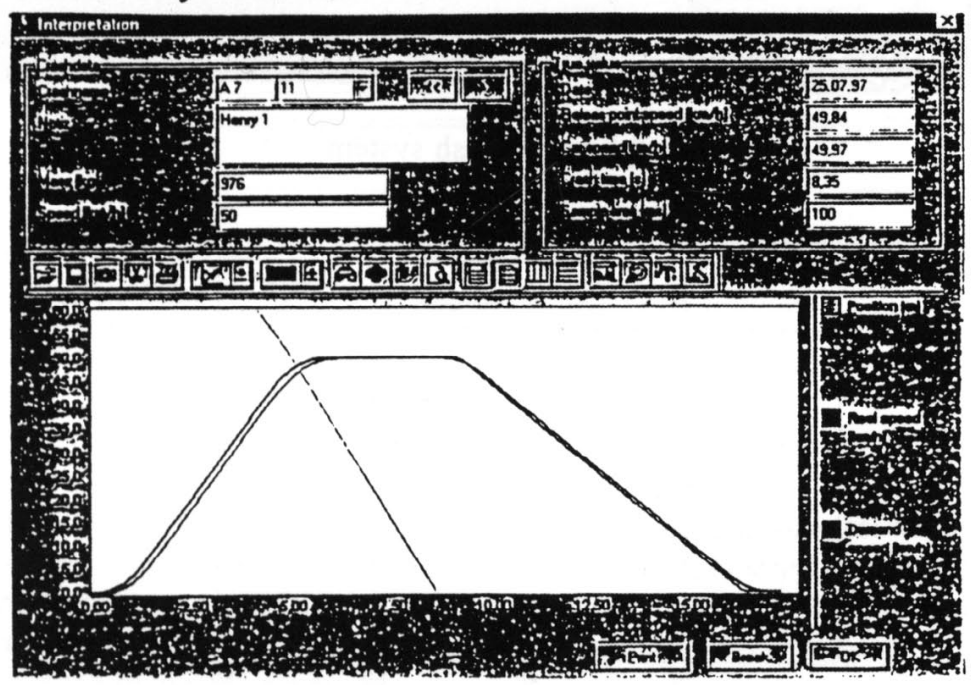

Fig. 3 Command and actual velocity and position of the drive 


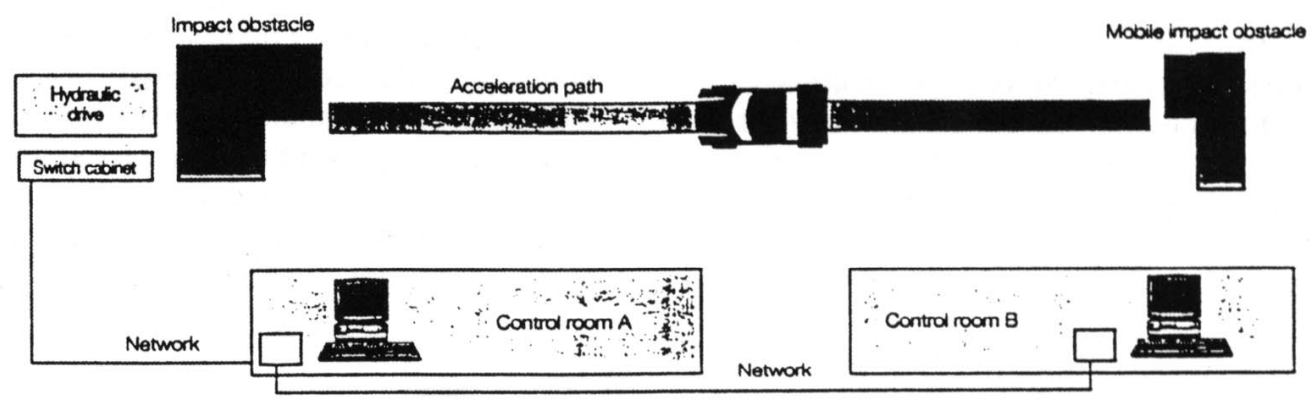

Fig. 4 Running against a fixed obstacle ( control room A), running against a movable obstacle (control room B)

\section{Inverse crash system}

In contrast to real crash tests, inverse crash tests are completely non-destructive with regard to the passenger compartment (Fig. 5). The object to be tested is mounted onto a carriage and accelerated backwards from velocity 0 up to the crash velocity (Fig. 6).

During this process, the test specimens or dummies are exposed to the, same effects as in a real collision. This type of test makes it possible to reuse the vehicle structure for the next test. The tests refer to active and passive safety features in the passenger compartment. Inverse crash systems are mainly used for the technical further development of these features.
As inverse crash tests are performed within a very short time ( 70 to 150 milliseconds), the entire power for the linear acceleration process is taken from the hydraulic accumulators. Depending on the mass of up to $3 t$ to be accelerated, the hydraulic power, which is made available by the accumulator station, reaches 35,000 $\mathrm{kW}$ to $40,000 \mathrm{~kW}$ at an operating pressure of 300 bar. On the other side, the installed electric power to charge the accumulator by means of an axial piston pump is only 90 to approx. $100 \mathrm{~kW}$. This relation shows that such a high-power system can only be realized in a useful manner using a hydraulic drive.

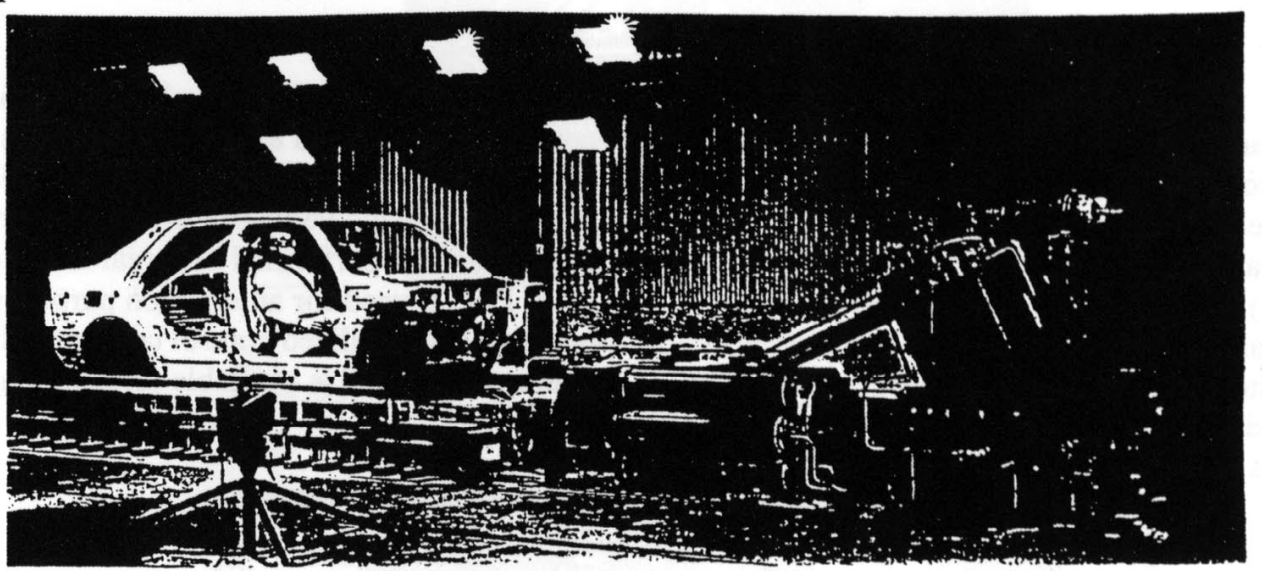

Fig. 5 Inverse crash system

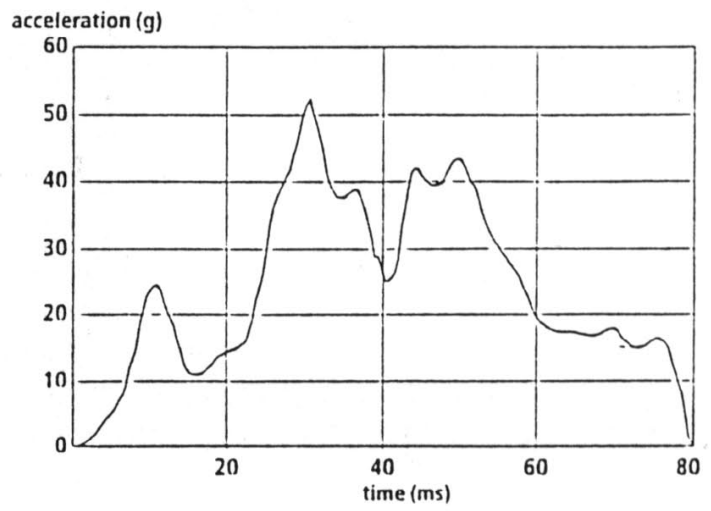

Fig. 6 Typical acceleration curve 


\subsection{The hydraulic-mechanical drive}

A servohydraulically controlled inverse crash system comprises the following subsystems (Fig. 7):

- Pressure accumulator

- Acceleration cylinder

- Servo-orifice

- Recovery accumulator

The pressure accumulators used are piston-type accumulators with nitrogen bottles connected downstream. During the acceleration phase, they provide a uniform operating pressure. At the beginning of the test, the accumulators are charged to an oil pressure of 300 bar so that a power of $37.5 \mathrm{MW}$ is briefly available which can be controlled by means of a servovalve. The acceleration cylinder with hydrostatic bearing is a single rod cylinder with a useful stroke of $1600 \mathrm{~mm}$. An additional stroke of $400 \mathrm{~mm}$ is used for end position cushioning, which decelerates the piston at the end of the acceleration stroke. The maximum operating velocity of the piston is rated so that the total oil flow can be up to $75,000 \mathrm{~V} / \mathrm{min}$. The servo logic valve of size 200 employed is a four-stage slide valve. As pilot valve it comprises a three-stage servovalve of size 37 with electrical feedback and a nominal flow of $1000 \mathrm{~V} / \mathrm{min}$. The $4^{\text {th }}$ stage with closed-loop position control is designed as single-land spool. The main stage pressurizes the piston chamber of the cylinder. The oil displaced on the cylinder's piston rod side due to the acceleration process is not returned to tank as in conventional hydraulic circuits, but is absorbed by 6 low-pressure piston-type accumulators. During the test, the extension movement of the piston rod causes the backward acceleration of the carriage onto which the body shell is rigidly mounted (Fig. 8). The carriage is guided on rails. The integrated braking system on the carriage is designed as a redundant system. It is supplemented by a mechanically acting emergency brake system at the end of the rails and a buffer at the end of the braking distance; with these systems only being activated if the two integrated braking systems should fail simultaneously. An electrically driven return device allows the carriage to be brought back to its docking position at the piston rod.

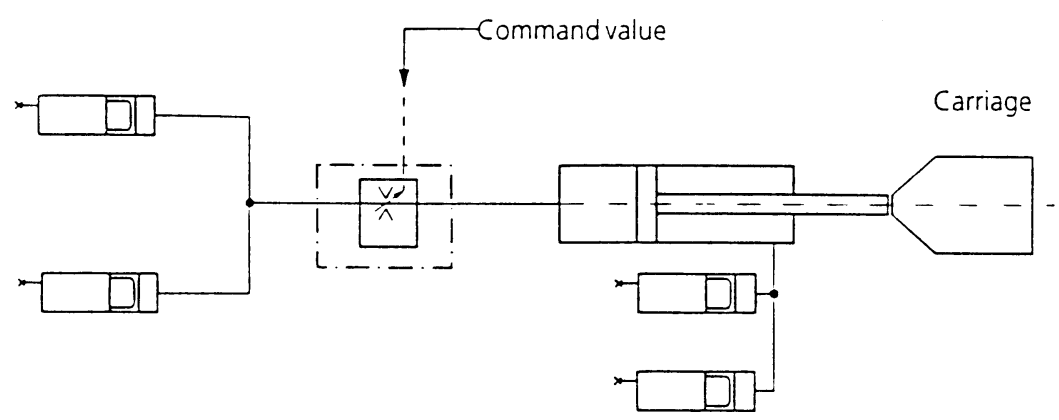

Fig. 7 Hydraulic drive principle of an inverse crash system

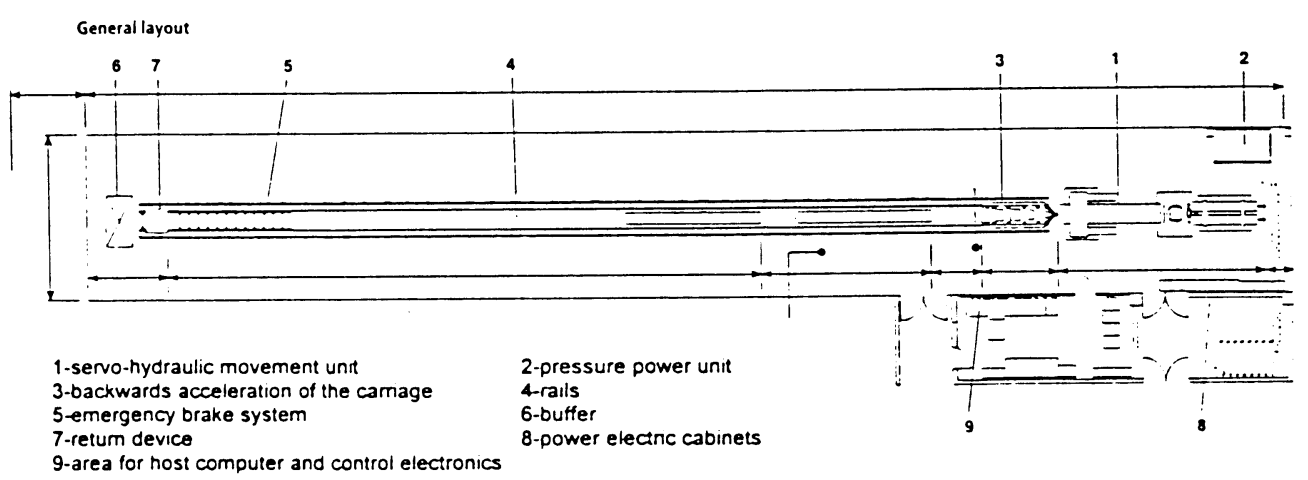

Fig. 8 Arrangement of an inverse crash system

\subsection{The control principle}

The command value generator calculates a valve command value from the acceleration command value taking into account the mathematical models of the entire system. This provides the requested actual acceleration value for the test (Fig. 9). For this, a nonlinear inverse system model is used, which calculates how the valve must be controlled to achieve the required acceleration profile. By doing without a 
feedback of the main status variable, dynamics are improved.

Since this is a purely open-loop control, all mathematically definable non-linearities can be taken into account without resulting into system instability. The process control software allows quasi offline calculation of the valve command value, which is used to carry out the first test. The valve command value, which is calculated using the simulation model, provides good results (Fig. 10). To further improve the correction of the valve command value, a second test is required. The drawn up correction procedure is based on the evaluation of acceleration differences from the previous test and the evaluation of various, measurable and non-measurable status variables of the system. In connection with this, one could speak of an offline closed-loop control. The correction procedure is characterized by a very good convergence so that the required accuracy of $\pm 1 \mathrm{~g}$ is achieved after one to three corrections depending on the acceleration curve. The system operator is therefore in a position to simulate a new acceleration curve first. He can then assess whether it is possible and useful to run a real crash test on the basis of this curve.

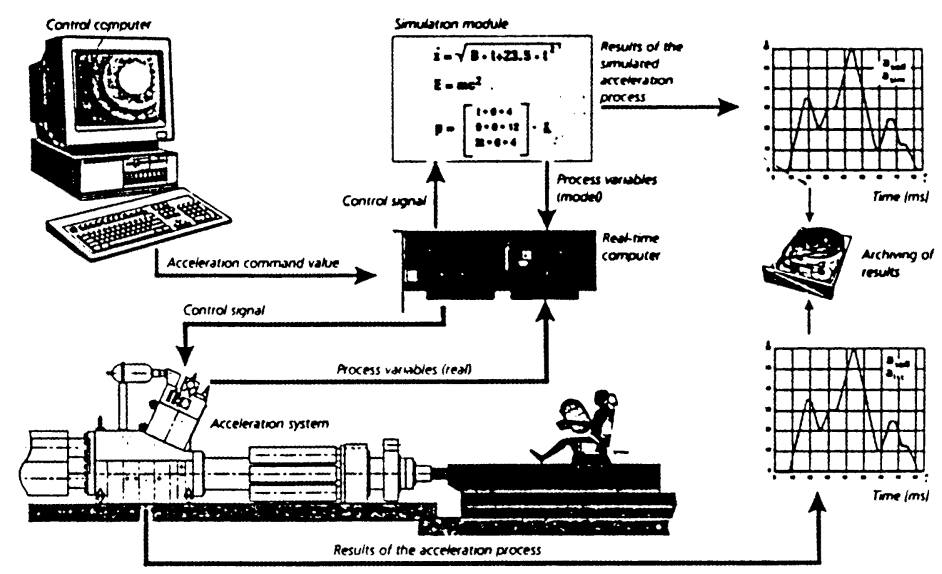

Fig. 9 Control, simulation and results administration

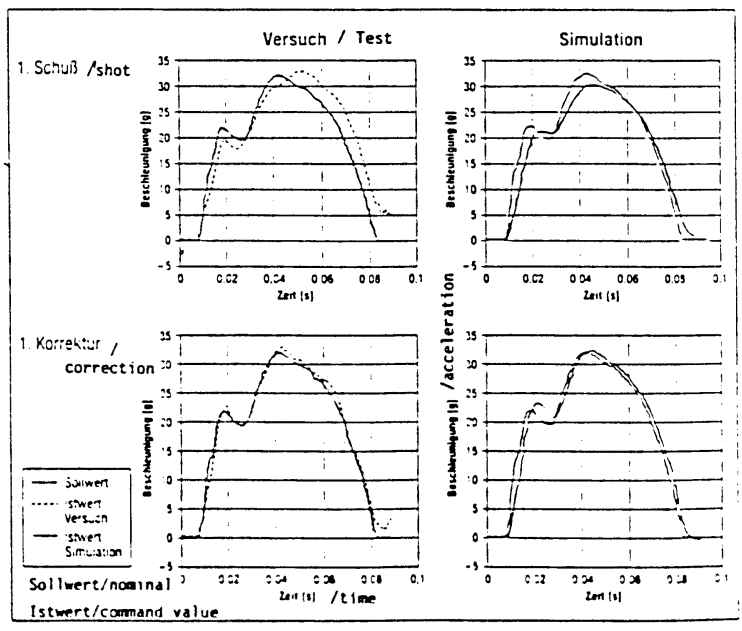

Fig. 10 Tests and simulation of acceleration

\section{Hydraulics for short-time accelerations}

Potential energy and its conversion into power within a few milliseconds is the main feature of a hydraulic drive. Short-time peak power must not be taken from the electric mains on the primary side, but can be called up via hydropneumatic accumulators on the secondary side. The real crash and inverse crash systems described here would hardly be feasible without the utilization of this technical advantage. 


\section{Conclusion}

Automotive manufacturers and suppliers are increasingly using servo hydraulic real crash and inverse crash systems for testing car safety features. The advantages of these tests are the exact repeatability, the variation of test parameters and the precise monitoring and analysis of test results. The safety of passenger relevant car subsystems and components can be dramatically increased and optimized without adding cost to the total safety package of the car. Airbags and seat belts are the predominant active safety systems to be tested. Items such as steering columns, dash board, pedals and doors are the passive safety systems which much be extensively tested under $\mathrm{g}$-forces. The inverse and real crash test facilities serve to this purpose. 